\title{
Effect of Herbal Extract Mixtures on Serum and Liver Lipid Metabolism in Chronic Ethanol - Administered Rats
}

\author{
Mok Kyung Kim, Sun Hee Hyun, and Se Young Choung* \\ Department of Hygienic Chemistry, College of Pharmacy, Kyung Hee University, 1 Hoeki-Dong, Dongdaemoon-Ku, Seoul 130-701, \\ Korea
}

(Received December 7, 2005; Accepted May 9, 2006)

\begin{abstract}
This study investigated the effects of mixtures of Vitis vinifera $(\mathrm{V})$, Schizandra chinensis $(\mathrm{S})$, Taraxacum officinale (T), Gardenia jasminoides (G), Angelica acutiloba (A), and Paeonia japonica (P) on fatty liver and hepatotoxicity induced by an ethanol liquid diet. Male Sprague-Dawley rats received a normal diet (ND), ethanol diet (ED), ED + VST (ethanol diet + V $100+$ S $150+$ T 150 mg/kg/day), ED + VGS (ethanol diet + V $100+$ G $150+$ S 150 mg/kg/ day), ED + VGT (ethanol diet + V $100+$ G $150+$ T $150 \mathrm{mg} / \mathrm{kg} /$ day), and ED + VAP (ethanol diet + V $100+\mathrm{A} 150$ + P $150 \mathrm{mg} / \mathrm{kg} /$ day). Rats fed liquid diets containing alcohol for 6 weeks showed remarkable increases in serum and hepatic lipid levels, indicating the onset of alcoholic fatty liver. Greater increases in alanine transaminase (ALT) and alkaline phosphatase (ALP) activities in serum were observed in the groups fed alcohol-containing diets compared with those in the ND group. Treatment with ED + VST, ED + VGS, ED + VGT, and ED + VAP decreased the levels of triglycerides, free fatty acids, and total cholesterol in the serum and liver, with a concomitant reduction in the activity of serum ALT and ALP. These data suggest that the plant extracts examined in this study can be utilized as a health functional food or new drug candidates for the treatment of fatty liver and hepatotoxicity induced by chronic alcohol consumption.
\end{abstract}

Key words — Vitis vinifera, Schisandra chinensis, Taraxacum officinale, Gardenia jasminoides, Angelica acutiloba, Paeonia japonica

\section{INTRODUCTION}

Chronic ethanol consumption has fatal effects on the main organs of the body, in particular by causing dysfunction of hepatocytes, which are responsible for key metabolic functions. Ethanol intake may also cause alcoholic hepatitis, fatty liver, and liver cirrhosis. ${ }^{1)}$

Therefore, in those who consume large amounts of alcohol for extended periods, it is important to devise a proper regimen to help prevent alcohol-induced syndromes. Recently, studies have utilized the acute toxicity model, whereby $\mathrm{CCl}_{4}{ }^{2)}$ or ethanol ${ }^{3)}$ is administered at excessive dosages to induce fatty liver or hepatitis in animal models. However, in view of the differences between animals and humans in relation to alcoholic fatty liver or hepatitis, in the

\footnotetext{
*To whom correspondence should be addressed: Department of Hygienic Chemistry, College of Pharmacy, Kyung Hee University, 1 Hoeki-Dong, Dongdaemoon-Ku, Seoul 130-701, Korea. Tel. \& Fax: +82-2-961-0372; E-mail: sychoung@khu.ac.kr
}

present study we chose to utilize a chronic alcoholic hepatotoxicity model to induce fatty liver.

Furthermore, various investigations on natural substances have been performed to determine whether they protect the liver from alcohol - induced hepatotoxicity. Of these, several natural extracts have been found to have noticeable protective effects on the liver and they were also subjected to comparative analysis in the present study.

The natural materials were grapeseeds, Omiza (Schizandra chinensis, S), Pogongyung (Taraxacum officinale, T), and gardenia (Gardenia jasminoides, $G)$, which have been reported to have noticeable protective effects on the liver against the hepatotoxicity caused by chronic alcohol consumption. The present study was designed to determine the combined administrative effects of the above natural materials, whereby grapeseed extracts were combined with one of the other three natural materials, i.e., Omiza, Pogongyung, and gardenia. We also examined the combined effects of grapeseed extracts with Danggi (Angelica gigas, A) and Jakyak 
(Paeonia lactiflora var. hortensis, $\mathrm{P}$ ).

Several types of procyanidins are present in grapeseed extracts (including catechin at up to $25 \%)^{4)}$; the main procyanidin is (+)-catechin. ${ }^{5)}$ It has been reported that the procyanidins in grapeseed extracts have antioxidative effects, ${ }^{6-11)}$ protective effects against cardiovascular disease, ${ }^{12)}$ antiinflammatory effects, antiviral effects, antiallergy effects, and artery - relaxant properties. ${ }^{13-17)}$

Omiza $(S)$ is a tree that belongs to the Magnolia family and has a hepatoprotective effect. It is well known that the administration of Omiza to normal rats results in reduced levels of neutral fatty acids in the serum, lipids in the liver, and the stimulation of drug - metabolizing enzyme activities. ${ }^{18,19)}$ In addition, it has also been reported to have antioxidative effects. ${ }^{20,21)}$ Hikino et al. found that Omiza had protective effects on the liver ${ }^{18)}$ and Lee and Lee found that it neutralized the poisonous effects of alcohol. ${ }^{22)}$

Pogongyung $(T)$ is a perennial herb that belongs to the Asteraceae family, and the herb is known to have beneficial effects in geriatric diseases, such as hypertension, heart disease, liver disease, and others. $^{23)}$

$\mathrm{G}$ is either a tree that belongs to the Rubiaceae family or a mature fruit obtained from other plants within the same family. The pharmacologic effects of gardenia were confirmed in an experiment showing that it suppresses serum cholesterol level increases, reduces lipid levels in the serum and in liver, ${ }^{24)}$ reduces the secretion of bile acid, ${ }^{25)}$ and inhibits hepatocyte dysfunction in white rats fed a highcarbohydrate diet.

Danggi (A. gigas) is a perennial herb belongings to the Umbelliferous family and it has been widely studied for its effects on immunity, ${ }^{26}$ antioxidative ability, ${ }^{27)}$ antimutagenic activity, ${ }^{28)}$ and anticancer activity. ${ }^{29)}$

Jakyak $(P)$ is a perennial herb belonging to the Buttercup family. Based on in vitro studies on its physiologic activities, it has noticeable antioxidative activity, ${ }^{30-32)}$ and it is reported that several solvent extracts from the roots of Jakyak are effective in lowering serum levels of cholesterol when levels are increased by a high cholesterol-containing diet. ${ }^{33)}$

Therefore this study was designed to determine the hepatoprotective effects in experimental rats chronically fed a Lieber-DeCarli ethanol diet. Mixtures of several natural materials such as grapeseed, Omiza, Pogongyung, and Gardenia, all of which have been reported to have noticeable effects against alcohol toxicity, were administered to Sprague-
Dawley SD rats. Effects on lipid metabolism in the serum were observed, and the livers of rats were examined to compare the hepatoprotective effects of various mixtures.

\section{MATERIALS AND METHODS}

Sample Preparation — Dried S, $T$, and $G$ were purchased from the Kyung-Dong (Seoul, Korea) market and distilled water was added at 10 -fold the volume to each. $\mathrm{G}$ was boiled at $60^{\circ} \mathrm{C}$ for $5 \mathrm{hr}$, while the other natural materials were extracted twice at $90^{\circ} \mathrm{C}$ for $4 \mathrm{hr}$. They were filtered, concentrated, and then freeze-dried. The yield of S and T was $40 \%, \mathrm{G}$ $29 \%$, A 54\%, and P 34\%. Grapeseed (Vitis vinifera, catechine $25 \%, \mathrm{~V}$ ) extracts were purchased from Herb Valley Co., Ltd.

Experimental Animals and Experimental Diets - Male SD white rats, 5 weeks old, weighing 140-150 g were purchased from Orient Inc. (Seoul, Korea) and used as an experimental animal model. The rats were adapted to solid feed for 1 week in the laboratory environment where the temperature was kept constant at $24.2^{\circ} \mathrm{C}$ and the humidity at $60 \%$ using a climate - control system. The 6 experimental groups $(n=8)$ each were fed an experimental diet for 6 weeks. The group with hepatotoxicity was orally administered prepared samples, and the control group was fed a diet without alcohol while simultaneously receiving the equivalent amount of distilled water. The experimental groups were designated the normal diet (ND), ethanol diet (ED), ED + $\mathrm{V} 100+\mathrm{S} 150+\mathrm{T} 150 \mathrm{mg} / \mathrm{kg} / \mathrm{day}(\mathrm{ED}+\mathrm{VST}), \mathrm{ED}$ $+\mathrm{V} 100+\mathrm{G} 150+\mathrm{S} 150 \mathrm{mg} / \mathrm{kg} / \mathrm{day}(\mathrm{ED}+\mathrm{VGS})$, $\mathrm{ED}+\mathrm{V} 100+\mathrm{G} 150+\mathrm{T} 150 \mathrm{mg} / \mathrm{kg} / \mathrm{day}(\mathrm{ED}+$ VGT), $\mathrm{ED}+\mathrm{V} 100+\mathrm{A} 150+\mathrm{P} 150 \mathrm{mg} / \mathrm{kg} /$ day $(\mathrm{ED}$ + VAP) groups.

The experimental diet was prepared according to the Lieber-DeCarli rat liquid diet method, ${ }^{34)}$ and was prepared fresh every day prior to use. Table 1 shows the compositions of the diets, which were designed to provide $1 \mathrm{kcal} / \mathrm{ml}$. The ED consisted of $35 \%$ fatty acids, $11 \%$ carbohydrate, $18 \%$ protein, and $36 \%$ ethanol, while the ND consisted of $35 \%$ fatty acids, $47 \%$ carbohydrate, and $18 \%$ protein. In the ED group, $36 \%$ of total calories was obtained from ethanol, while maltose dextrin corresponding to the amount of the above calories replaced ethanol in the ND group. The 5 ED groups were adapted to increasing amounts of ethanol for the first 4 days and then received ethanol ( $36 \%$ of total calories) for the 
Table 1. Composition of Experimental Diets (g/l)

\begin{tabular}{|c|c|c|}
\hline Ingredient & Normal diet & Ethanol diet \\
\hline Casein & 41.4 & 41.4 \\
\hline L-cysteine & 0.50 & 0.50 \\
\hline DL-methionine & 0.30 & 0.30 \\
\hline Corn oil & 8.50 & 8.50 \\
\hline Olive oil & 31.10 & 31.10 \\
\hline Safflower oil & 2.70 & 2.70 \\
\hline Dextrin maltose & 115.20 & 25.60 \\
\hline Cellulose & 10.00 & 10.00 \\
\hline Choline bitartrate & 0.53 & 0.53 \\
\hline Xantan gum & 3.00 & 3.00 \\
\hline Vitamin $\operatorname{mix}^{a}$ ) & 2.55 & 2.55 \\
\hline Mineral mix $\left.{ }^{b}\right)$ & 8.75 & 8.75 \\
\hline Ethanol & - & 54.51 \\
\hline
\end{tabular}

a) AIN-76A vitamin mix provided the following $(\mathrm{g} / \mathrm{kg})$ mix: thiamine $\mathrm{HCl}, 0.6$; riboflavin, 0.6 ; pyridoxine $\mathrm{HCl}, 0.7$; niacin, 3; calcium pantothenate, 1.6; folic acid, 0.2 ; biotin, 0.02 , vita$\min \mathrm{B}_{12}(0.1 \%), 1$; vitamin A palmitate $(500000 \mathrm{IU} / \mathrm{g}), 0.8$; vi$\operatorname{tamin} \mathrm{D}_{3}(400000 \mathrm{IU} / \mathrm{g}), 0.25$; vitamin $\mathrm{E}$ acetate $(500 \mathrm{IU} / \mathrm{g}), 10$; menadione sodium isulfite, 0.08 ; sucrose, finely powdered, 981.15 ; Dyets, Bethelchem, Pennsylvania, U.S.A. b) AIN-76 mineral mix provided the following $(\mathrm{g} / \mathrm{kg})$ mix: calcium phosphate, dibasic, 500; codium chloride, 74; potassium citrate $\mathrm{H}_{2} \mathrm{O}, 220$; potassium sulfate, 52; magnesium oxide, 24; manganous carbonate, 3.5; ferric citrate. 6 ; zinc carbonate, 1.6 ; cupric carbonate, 0.3 ; potassium iodate, 0.01 ; sodium selenite, 0.01 ; chromium $\mathrm{K}$ sulfate, $12 \mathrm{H}_{2} \mathrm{O}, 0.5$; sucrose, finely powdered, 118.03; Dyets, Bethelchem, Pennsylvania, USA.

next 5 days to 6 weeks. The amount of diet and weight were observed at a constant interval twice a week.

Sampling Procedures — The experimental animals were fasted for $12 \mathrm{hr}$ and then anesthetized with ether. Blood samples were collected from the hepatic portal vein and centrifuged at $3000 \mathrm{rpm}$ for $10 \mathrm{~min}$. The serum was stored at $-70^{\circ} \mathrm{C}$ until analyzed. The liver was removed, weighed after being cleaned with ice-cold saline, and stored at $-70^{\circ} \mathrm{C}$ for lipid analysis.

Biochemical Analyses _ Levels of triglyceride (TG), total cholesterol (TC), and high-density lipoprotein cholesterol (HDL-C) in serum were determined colorimetrically using an enzyme-mediated kit (Asan Diagnostics, Seoul, Korea). Levels of free fatty acids (FFA) in serum were determined using a commercial enzymatic procedure (NEFA-HR kit, ACS-ACOD Method; Wako Pure Chemical Industries, Osaka, Japan).

Analysis of lipids in the liver was performed by first extracting lipids by the method devised by Folch et al. ${ }^{35)}$ Briefly, $1 \mathrm{~g}$ of tissue is homogenized with
Table 2. Reducing Effects of Herbal Extract Mixtures on Body Weight and Liver Index in Ethanol-Administered Rats

\begin{tabular}{lll}
\hline \hline Group & $\begin{array}{c}\text { Body weight } \\
(\mathrm{g})\end{array}$ & $\begin{array}{l}\text { Liver index }^{a)} \\
(\mathrm{g} / \mathrm{BW} 100 \mathrm{~g})\end{array}$ \\
\hline ND & $324.0 \pm 31.4$ & $2.77 \pm 0.22$ \\
ED & $264.0 \pm 25.5^{*}$ & $3.27 \pm 0.35^{*}$ \\
ED + VST & $276.9 \pm 51.8^{*}$ & $2.68 \pm 0.12^{\dagger}$ \\
ED + VGS & $281.0 \pm 35.6^{*}$ & $2.95 \pm 0.21^{\dagger}$ \\
ED + VGT & $296.9 \pm 24.5$ & $2.86 \pm 0.26^{\dagger}$ \\
ED + VAP & $304.3 \pm 27.2$ & $3.08 \pm 0.40$ \\
\hline
\end{tabular}

Values are mean \pm S.D. Significantly different from normal diet (ND) group at ${ }^{*} p<0.05$. Significantly different from ethanol diet (ED) group at ${ }^{\dagger} p<0.05$. a) Liver index = liver/body weight.

chloroform/methanol $(2: 1)$ to a final volume of 20 -fold the volume of the tissue sample for $2 \mathrm{~min}$. After dispersion, the mixture is agitated for 15$20 \mathrm{~min}$ in an orbital shaker at room temperature. The homogenate is centrifuged to recover the liquid phase. The solvent is washed with a 0.2 volume of $0.9 \% \mathrm{NaCl}$ solution. After vortexing for several seconds, the mixture is centrifuged at $2000 \mathrm{rpm}$ to separate the two phases. After centrifugation and removal of the upper phase, the lower chloroform phase containing lipids is evaporated under a vacuum in a rotary evaporator if the volume is less than $2-3 \mathrm{ml}$ and analyzed using the same method as for serum. For alanine transaminse (ALT) in serum, analysis was performed with a kit (Asan Diagnostics) using the Reitman-Frankel method ${ }^{36)}$ and for alkaline phosphatase (ALP), analysis was performed with a kit (Asan Diagnostics) using the Kind-King method. ${ }^{37)}$ Statistical Analysis — The results are presented as mean \pm standard deviation (S.D.). Data were analyzed using the Statistical Analysis System (SAS) program. Differences between the control and ED groups were analyzed with Duncan's multiple-range tests. A value of $p<0.05$ was considered to represent a statistically significant difference.

\section{RESULTS}

\section{Change in Body and Liver Weights}

We studied the effects of administering herbal extract mixtures (HEM) for 6 weeks on rat body and liver weights (Table 2). Body weights were significantly lower in the ED group than in the ND group. HEM-treated groups did not significantly differ in liver and body weight from those in the ND group. But HEM-treated groups showed slower body weight 
Table 3. Effects of Herbal Extract Mixtures on Serum Triglyceride, Free Fatty Acid, Total Cholesterol, and HDL Cholesterol Levels in Ethanol-Administered Rats

\begin{tabular}{llllc}
\hline \hline & TG $(\mathrm{mg} / \mathrm{dl})$ & FFA $(\mu \mathrm{Eq} / \mathrm{l})$ & TC $(\mathrm{mg} / \mathrm{dl})$ & HDL-C $(\mathrm{mg} / \mathrm{dl})$ \\
\hline ND & $36.66 \pm 6.81$ & $0.49 \pm 0.06$ & $50.20 \pm 9.46$ & $41.44 \pm 11.28$ \\
ED & $76.73 \pm 14.25^{*}$ & $0.63 \pm 0.06^{*}$ & $73.58 \pm 13.86^{*}$ & $37.84 \pm 11.59$ \\
ED + VST & $39.34 \pm 6.81^{\ddagger}$ & $0.55 \pm 0.06^{\dagger}$ & $54.77 \pm 11.33^{\dagger}$ & $40.68 \pm 7.12$ \\
ED + VGS & $41.75 \pm 16.79^{\ddagger}$ & $0.62 \pm 0.02^{*}$ & $57.27 \pm 7.30^{\dagger}$ & $32.65 \pm 8.93$ \\
ED + VGT & $39.07 \pm 13.31^{\ddagger}$ & $0.60 \pm 0.03^{*}$ & $63.24 \pm 12.42$ & $32.62 \pm 5.30$ \\
ED + VAP & $52.25 \pm 10.75^{*}$, & $0.59 \pm 0.06^{*}$ & $67.31 \pm 6.76^{*}$ & $39.41 \pm 3.04$ \\
\hline
\end{tabular}

Values are mean \pm S.D. Significantly different from normal diet (ND) group at $* p<0.05$. Significantly different from ethanol diet (ED) group at ${ }^{\dagger} p<0.05$ and ${ }^{\dagger} p<0.01$, respectively.

gain than the ED group. It is considered that the reasons for this decrease in body weight gain are a result of the increased oxygen uptake due to alcohol consumption, an increase in metabolic rates, and a reduction in the production of ATP through alcohol oxidation in microsomes. ${ }^{38)}$

The ED group showed an $18 \%$ increase in the liver index compared with that in the ND group. HEM-treated groups had reduced liver weights compared with the ED group. The ED + VST, ED + VGS and ED + VGT groups had values similar to that of the ND group because their liver weights were significantly reduced by alcohol.

\section{Levels of Triglycerides and Free Fatty Acids in Serum}

Levels of TG and FFA are shown in Table 3. The results were obtained after feeding alcohol in diet for 6 weeks. The levels of TG and FFA in serum were markedly affected by the experimental diets. TG values in the ED group were about two-fold higher than those in the ND group. This confirmed that toxicity was induced by the ingestion of ethanol. Compared with the ED group, there was a decrease of $48.7 \%$ in the ED + VST group, of $45.6 \%$ in the ED + VGS group, of $49.1 \%$ in the ED + VGT groups, and of $31.9 \%$ in the ED + VAP group. All HEM-treated groups had significantly decreases in their TG values compared with those in the ED group. In particular, values in the ED + VST and $\mathrm{ED}+$ VGT groups decreased to the level in the ND group. FFA levels showed a similar tendency to TG levels, where the ED group showed a $29 \%$ increase compared to that in the ND group. HEM-treated groups had lower levels compared with those in the ED group, whereas the ED + VST group had significantly decreased FFA levels.

\section{TC and HDL-C in Serum}

Levels of TC and HDL-C in each group are shown in Table 3. The ED groups showed a $47 \%$ increase in TC and HDL-C levels compared with the ND group. Pikaar et al. reported that the longterm consumption of alcohol results in an increase in serum. ${ }^{39)}$ HEM-treated groups showed a tendency toward lower total TC levels compared with the ED groups, especially the ED + VST and ED + VGS groups, which showed significant decreases versus the ED group. No significant differences were observed between groups in HDL-C levels, although the ED + VST and ED + VAP groups tended to have higher levels than the ED group. Based on these results, HEM reduced levels of TG, FFA, and TC and enhanced HDL-C levels in the serum of rats given alcohol long term.

\section{Changes in Liver Tissue Lipids}

Changes in liver tissue lipids after receiving an alcohol diet for 6 weeks are shown in Table 4. The ED groups had about a 79\% increase in TG levels compared with the ND group. HEM-treated groups showed a tendency toward lower values compared with those in the ED groups. In particular, the ED + VST and ED + VGS groups both showed significantly decreased TC levels. Similarly, levels of FFA in the ED group were significantly (about 43\%) higher than those in the ND group. There were no distinct differences between the groups in TC levels. Therefore HEM reduced levels of TG, FFA, and $\mathrm{TC}$ in liver tissues of rats fed long-term dosages of alcohol.

\section{ALT and ALP Activity in Serum}

The effects of HEMs on the alcohol-induced elevation of ALT and ALP activities are presented in Table 5. ALT values in the ED group were significantly higher than in the ND group. Among the 
Table 4. Reducing Effects of Herbal Extract Mixtures on Liver Triglyceride, Free Fatty Acid, and Total Cholesterol Levels in Ethanol-Administered Rats

\begin{tabular}{|c|c|c|c|}
\hline & TG (mg/g liver) & FFA ( $\mu$ Eq/g liver $)$ & TC (mg/g liver) \\
\hline ND & $2.97 \pm 0.58$ & $0.94 \pm 0.14$ & $11.69 \pm 1.06$ \\
\hline ED & $5.32 \pm 1.90^{*}$ & $1.34 \pm 0.25^{*}$ & $11.86 \pm 3.50$ \\
\hline $\mathrm{ED}+\mathrm{VST}$ & $3.17 \pm 1.33^{\dagger}$ & $0.81 \pm 0.22^{\ddagger}$ & $10.33 \pm 1.81$ \\
\hline $\mathrm{ED}+\mathrm{VGS}$ & $3.46 \pm 1.64^{\dagger}$ & $0.88 \pm 0.27^{\dagger}$ & $11.01 \pm 0.55$ \\
\hline $\mathrm{ED}+\mathrm{VGT}$ & $4.28 \pm 0.55$ & $0.81 \pm 0.16^{\ddagger}$ & $11.47 \pm 0.22$ \\
\hline $\mathrm{ED}+\mathrm{VAP}$ & $5.45 \pm 0.90^{*}$ & $0.64 \pm 0.10^{*, \ddagger}$ & $12.22 \pm 2.89$ \\
\hline
\end{tabular}

Table 5. Protective Effects of Herbal Extract Mixtures on Serum ALT and ALP Values in EthanolAdministered Rats

\begin{tabular}{lcl}
\hline \hline & ALT (Karmen/ml) & ALP (20K-A) \\
\hline ND & $31.03 \pm 2.62$ & $22.79 \pm 4.19$ \\
ED & $39.84 \pm 6.58^{*}$ & $27.59 \pm 7.18$ \\
ED + VST & $31.60 \pm 2.43^{\dagger}$ & $19.16 \pm 2.64^{\dagger}$ \\
ED + VGS & $25.38 \pm 3.29^{*}$, & $22.21 \pm 3.93$ \\
ED + VGT & $25.90 \pm 1.71^{*} \dagger$ & $22.49 \pm 3.41$ \\
ED + VAP & $37.99 \pm 3.12^{*}$ & $23.95 \pm 6.76$ \\
\hline
\end{tabular}

Values are mean \pm S.D. Significantly different from normal diet (ND) group at $* p<0.05$. Significantly different from ethanol diet (ED) group at ${ }^{\dagger} p<0.05$.

HEM-treated groups, the ED + VST groups had values similar to that of the ND group, and levels in the $\mathrm{ED}+\mathrm{VGS}$ group and the ED + VGT group were significantly lower than that in the ND group because of alcohol consumption. ALP values did not change significantly after alcohol consumption, although the ALP value in the ED group increased by $21 \%$ compared with that in the ND group. HEMtreated groups showed a tendency toward lower ALP values compared with those of the ED groups, especially in the ED + VST group that showed a marked reduction in ALP values compared with the ND group.

\section{DISCUSSION}

The rats fed an alcohol-containing diet for 6 weeks showed significant weight loss versus the ND group, which concurs with a report that weight loss occurs in chronic alcohol abusers because of decreased food intake and malabsorption. ${ }^{1)}$ Pikaar et al. reported that weight loss due to alcohol consumption in patients is mainly attributable to a loss in body fat, a reduction in the amount of diet con- sumed, and sharp increase in energy consumption. ${ }^{39)}$ HEMs used in this study restored animals to normal weight after weight loss due to the administration of an ethanol-containing diet.

It is considered that the liver weights per $100 \mathrm{~g}$ of body weight in the experimental groups increased significantly due to the increased volumes of cells caused by the accumulation of fats, proteins, and water in alcohol-induced cirrhosis of the liver. ${ }^{40)}$ The administration of VST, VGS, and VGT HEMs significantly reduced the liver index.

As a result of our investigation of changes in lipid metabolism in livers injured by long-term alcohol ingestion, we found that groups fed alcoholcontaining diets had increased levels of TG and FFA in serum compared with the ND group. This is concurs with the findings of studies that showed the development of hyperlipidemia through the longterm intake of alcohol. ${ }^{41,42)}$

The administration of several HEMs led to a markedly lower overall concentration of TG which was increased by feeding the alcohol-containing diet. The concentration of FFA was also significantly decreased by HEMs.

In addition, the concentration of TC in the alcohol-fed groups was higher than in the ND group, which agreed with a report by Pikaar et al. ${ }^{39)}$ that increased levels of TC in serum are directly linked to chronic alcohol intake. The present study confirms that the administration of VST and VGS lowers elevated TC concentrations due to chronic alcohol intake.

Increased levels of TG, FFA, and TC in the liver were observed in groups fed alcohol-containing diets as compared with the ND group. Dutta et al. ${ }^{43)}$ explained that fatty liver develops as a result of chronic alcohol intake, and that this is the result of malnutrition due to a reduction in food consumption and in particular to a lack of anti-fatty liver fac- 
tors, such as proteins, methionine, choline, vitamin $\mathrm{E}, \mathrm{Se}$, and others. Situnayake et al ${ }^{44)}$ reported that $\mathrm{ADH}$ and ALAH are NAD-dependent enzymes, which participate in the oxidation of alcohol. When alcohol is consumed on a chronic basis, NAD is converted into $\mathrm{NADH}$, which may induce changes in the redox state of the liver and cause the accumulation of TG in liver. Suter et al. ${ }^{45)}$ reported that the oxidation of lipids was greatly reduced by alcohol intake. In the present study, several HEMs markedly reduced the concentrations of TG, FFA, and TC in the liver, especially in the VST and VGS groups. The above results show that the HEMs used in this study prevent the accumulation of lipids due to chronic alcohol consumption.

Increased activities of serum ALT and ALP may signal the onset of hepatic dysfunction. ${ }^{46}$ All activities of ALT and ALP in the groups fed ethanol-containing diets increased compared with those in the ND group, which resulted from liver injury caused by chronic alcohol consumption. The present study shows that the administration of HEMs effectively improved liver function by lowering the activities of ALT and ALP.

Our study showed that the ED + VST, ED + VGS, and ED + VGT groups were effectively protected against liver toxicity from chronic alcohol exposure and lipid metabolism in both the liver and serum was protected compared with the ED + VAP group. This result agrees with those from previous comparative studies on herbal materials. We found that the ED + VST group was the most effectively protected.

We confirmed that the HEMs examined in this study are effective in improving liver functions and treating liver dysfunction and lipid metabolism disorders induced by chronic alcohol consumption in an experimental rat model, which has been confirmed to reflect alcohol-induced liver disease in humans. In addition, the HEMs play a role in preventing or reducing alcohol-induced hepatoxicity. Further studies on the effects of these HEMs on alcohol and lipid metabolism are required.

\section{REFERENCES}

1) Lieber, C. S. (1994) Alcohol and the liver: 1994 update. Gastroenterology, 106, 1085-1105.

2) Lin, K. J., Chen, J. C., Tsauer, W., Lin, C. C., Lin, J. G. and Tsai, C. C. (2001) Prophylactic effect of four prescriptions of traditional Chinese medicine on al- pha-naphthylisothiocyanate and carbon tetrachloride induced toxicity in rats. Acta Pharmacol. Sin., 22, 1159-1167.

3) Schlorff, E. C., Husain, K. and Somani, S. M. (1999) Dose- and time-dependent effects of ethanol on plasma antioxidant system in rat. Alcohol, 17, 97105.

4) Simonetti, P., Ciappellano, S., Gardana, C., Bramati, L. and Pietta, P. (2002) Procyanidins from Vitis vinifera seeds: in vivo effects on oxidative stress. $J$. Agric. Food Chem., 50, 6217-6221.

5) Yilmaz, Y. and Toledo, R. T. (2004) Major flavonoids in grape seeds and skins: antioxidant capacity of catechin, epicatechin, and gallic acid. J. Agric. Food Chem., 52, 255-260.

6) Facino, R. M., Carini, M., Aldini, G., Berti, F., Rossoni, G., Bombardelli, E. and Morazzoni, P. (1999) Diet enriched with procyanidins enhances antioxidant activity and reduces myocardial postischaemic damage in rats. Life Sci., 64, 627-642.

7) Govindarajan, R., Vijayakumar, M., Rao, C. V., Shirwaikar, A., Rawat, A. K., Mehrotra, S. and Pushpangadan, P. (2004) Antioxidant potential of Anogeissus latifolia. Biol. Pharm. Bull., 27, 12661269.

8) Maffei Facino, R., Carini, M., Aldini, G., Calloni, M. T., Bombardelli, E. and Morazzoni, P. (1998) Sparing effect of procyanidins from Vitis Vinifera on vitamin E: in vitro studies. Planta Med., 64, 343347.

9) Bagchi, D., Garg, A., Krohn, R. L., Bagchi, M., Tran, M. X. and Stohs, S. J. (1997) Oxygen free radical scavenging abilities of vitamins $\mathrm{C}$ and $\mathrm{E}$, and a grape seed proanthocyanidin extract in vitro. Res. Commun. Mol. Pathol. Pharmacol., 95, 179-189.

10) Carini, M., Aldini, G., Bombardelli, E., Morazzoni, P. and Maffei Facino, R. (2000) UVB-induced hemolysis of rat erythrocytes: protective effect of procyanidins from grape seeds. Life Sci., 67, 17991814.

11) Ghiselli, A., Serafini, M., Maiani, G., Azzini, E. and Ferro-Luzzi, A. (1995) A fluorescence-based method for measuring total plasma antioxidant capability. Free Radic. Biol. Med., 18, 29-36.

12) Aldini, G., Carini, M., Piccoli, A., Rossoni, G. and Faino, R. M. (2003) Procyanidins from grape seeds protect endothelial cells from peroxynitrite damage and enhance endothelium-dependent relaxation in human artery: new evidences for cardio-protection. Life Sci., 73, 2883-2898.

13) Packer, L., Rimbach, G. and Virgili, F. (1999) Antioxidant activity and biologic properties of a procyanidin-rich extract from pine (Pinus maritima) bark, pycnogenol. Free Radic. Biol. Med., 27, 704724. 
14) Fitzpatrick, D. F., Bing, B. and Rohdewald, P. (1998) Endothelium dependent vascular effects of pycnogenol. J. Cardiovasc. Pharmacol., 32, 509515.

15) Pellegrini, N., Pareti, F. I., Stabile, F., Brusamolino, A. and Simonetti, P. (1996) Effects of moderate consumption of red wine on platelet aggregation and haemostatic variables in healthy volunteers. Eur. J. Clin. Nutr., 50, 209-213.

16) Cheshier, J. E., Ardestani-Kaboudanian, S., Liang, B., Araghiniknam, M., Chung, S., Lane, L., Castro, A. and Watson, R. R. (1996) Immunomodulation by pycnogenol in retrovirus infected or ethanol fed mice. Life Sci., 58, 87-96.

17) Sanbongi, C., Suzuki, N. and Sakane, T. (1997) Polyphenols in chocolate, which have antioxidant activity, modulate immune functions in humans in vitro. Cell. Immunol., 177, 129-136.

18) Hikino, H., Kiso, Y., Taguchi, H. and Ikeya, Y. (1984) Antihepatotoxic actions of lignoids from Schizandra chinensis fruits. Planta Med., 50, 213-218.

19) Maeda, S., Takeda, S., Miyamoto, Y., Aburada, M. and Harada, M. (1985) Effects of gomisin A on liver functions in hepatotoxic chemicals-treated rats. Jpn. J. Pharmacol., 38, 347-353.

20) Toda, S., Tanizawa, H., Arichi, S. and Takino, Y. (1984) Inhibitory effects of methanol extracts of crude drugs on the air oxidation of linoleic acid. Yakugaku Zasshi, 104, 394-397.

21) Ikeya, Y., Taguchi, H., Mitsuhashi, H., Sasaki, H., Matsuzaki, T., Aburada, M. and Hosoya, E. (1988) Studies on the metabolism of gomisin A (TJN-101). I. Oxidative products of gomisin A formed by rat liver S9 mix. Chem. Pharm. Bull., 36, 2061-2069.

22) Lee, J. S. and Lee, S. W. (1990) Effect of water extract in fruits of Omija (Schizandra chinensis Baillon) on alcohol metabolism. Korean J. Dietary Culture, 5, 259-262.

23) Kim, K. H., Chun, H. J. and Han, Y. S. (1998) Screening of antimicrobial activity of the dandelion (Taraxacum platycarpum) extracts. Korean J. Soc. Food Sci., 44, 114-118.

24) Kimura, Y., Okuda, H. and Arichi, S. (1982) Effects of geniposide isolated from Gardenia jasminoides on metabolic alterations in high sugar diet-fed rats. Chem. Pham. Bull., 30, 4444-4447.

25) Sasaki, T., Ohta, S., Kamogawa, A. and Shinoda, M. (1989) Choleretic effects of methanol extracts obtained from various Chinese traditional medicine. Yakugaku Zasshi, 109, 487-495.

26) Han, S. B., Kim, Y. H., Lee, C. W., Park, S. M., Lee, H. Y., Ahn, K. S., Kim, I. H. and Kim, H. M. (1998) Characteristic immunostimulation by angelan isolated from Angelica gigas Nakai. Immunopharmacology, 40, 39-48.
27) Wu, H., Kong, L., Wu, M. and Xi, P. (1996) Effects of different processed products of radix Angelica sinensis on clearing out oxygen free radicals and anti-lipid peroxidation. Zhongguo Zhong Yao Za Zhi, 21, 599-601, 639.

28) Salikhova, R. A. and Poroshenko, G. G. (1995) Antimutagenic properties of Angelica archangelica L. Vestn. Ross. Akad. Med. Nauk., 1, 58-61.

29) Okuyama, T., Takata, M., Takayasu, J., Hasegawa, T., Tokuda, H., Nishino, A., Nishino, H. and Iwashima, A. (1991) Anti-tumor-promotion by principles obtained from Angelica keiskei. Planta Med., 57, 242-246.

30) Song, J. C., Park, N. K., Hur, H. S., Bang, M. H. and Beak, N. I. (2000) Examination and isolation of natural antioxidants from Korean medicinal plants. Korean J. Medicinal Crop. Sci., 8, 94-101.

31) Rim, Y. S., Park, Y. M., Park, M. S., Kim, K. Y., Kim, M. J. and Choi, Y. H. (2000) Screening of antioxidants and antimicrobial activity in native plants. Korean J. Medicinal Crop. Sci., 8, 342-350.

32) Lee, S. J., Lee, I. S. and Mar, W. (2003) Inhibition of inducible nitric oxide synthase and cyclooxygenase- 2 activity by 1,2,3,4,6-penta-Ogalloyl-beta-D-glucose in murine macrophage cells. Arch. Pharm. Res., 26, 832-839.

33) Ro, H. S., Ko, W. K., Yang, H. O., Park, K. K., Cho, Y. H., Lee, Y. E. and Park, H. S. (1999) Isolation of antihyperlipidemic substances from methanol extract of Paeoniae radix. J. Kor. Pharm. Sci., 29, 55-60.

34) Lieber, C. S. and DeCarli, L. M. (1982) The feeding of alcohol in liquid diets: two decades of applications and 1982 update. Alcohol Clin. Exp. Res., 6, 523-531.

35) Folch, J., Lees, M. and Sloane Stanley, G. H. (1957) A simple method for the isolation and purification of total lipids from animal tissues. J. Biol. Chem., 226, 497-509.

36) Reitman, S. and Frankel, S. (1957) A colorimetric method for the determination of serum glutamic oxalacetic and glutamic pyruvic transaminases. Am. J. Clin. Pathol., 28, 56-63.

37) Kind, P. R. N. and King, I. J. (1954) Estimation of plasma phosphatase by determination of hydrolyzed phenol with amino-antipyrine. J. Clin. Pathol., 7, 322-326.

38) Gruchow, H. W., Sobocinski, K. A., Barboriak, J. J. and Scheller, J. G. (1985) Alcohol consumption, nutrient intake and relative body weight among U.S. adults. Am. J. Clin. Nutr., 42, 289-295.

39) Pikaar, N. A., Wedel, M., van der Beek, E. J., van Dokkum, W., Kempen, H. J., Kluft, C., Ockhuizen, T. and Hermus, R. J. (1987) Effects of moderate alcohol consumption on platelet aggregation fibrinolysis and blood lipids. Metabolism, 36, 538-543. 
40) Lieber, C. S. (1985) Alcohol and the liver: metabolism of ethanol, metabolism effects and pathogenesis of injury. Acta Med. Scand. Suppl., 703, 11-55.

41) Woollett, L. A., Baldner-Shank, G. L., Aprahamian, S., Engen, R. L. and Beitz, D. C. (1987) Adaptation of lipogenesis and lipolysis to dietary ethanol. Alcohol Clin. Exp. Res., 11, 336-339.

42) Savolainen, M. J., Baraona, E., Leo, M. A. and Lieber, C. S. (1986) Pathogenesis of the hypertriglyceridemia at early stages of alcoholic liver injury in the baboon. J. Lipid Res., 27, 1073-1083.

43) Dutta, S. K., Miller, P. A., Greenberg, L. B. and Levander, O. A. (1983) Selenium and acute alco- holism. Am. J. Clin. Nutr., 38, 713-718.

44) Situnayake, R. D., Crump, B. J., Thurnham, D. I., Davies, J. A., Gearty, J. and Davis, M. (1990) Lipid peroxidation and hepatic antioxidants in alcoholic liver disease. Gut, 31, 1311-1317.

45) Suter, P. M., Schutz, Y. and Jequier, E. (1992) The effect of ethanol on fat storage in healthy subjects. N. Engl. J. Med., 326, 983-987.

46) Kukielka, E., Dicker, E. and Cederbaum, A. I. (1994) Increased production of reactive oxygen species by rat liver mitochondria after chronic ethanol treatment. Arch. Biochem. Biophys., 309, 377-386. 